\title{
Upfront surgery is not advantageous compared to more conservative treatments such as observation or medical treatment for patients with desmoid tumors
}

Shinji Tsukamoto ${ }^{1 *}$ (D, Piergiuseppe Tanzi ${ }^{2}$, Andreas F. Mavrogenis ${ }^{3}$, Manabu Akahane ${ }^{4}$, Akira Kido ${ }^{5}$, Yasuhito Tanaka ${ }^{1}$, Marilena Cesari ${ }^{6}$, Davide Maria Donati ${ }^{2}$, Alessandra Longhi ${ }^{6}$ and Costantino Errani ${ }^{2}$

\begin{abstract}
Background: This study compared the clinical and functional outcomes of patients initially treated with observation or medical treatment with those of patients treated with local treatment (surgery alone or surgery with adjuvant radiotherapy) to confirm whether observation or medical treatment is an appropriate first-line management approach for patients with desmoid tumors.

Methods: We retrospectively reviewed the medical records of 99 patients with histologically confirmed primary desmoid tumors treated between 1978 and 2018. The median follow-up period was 57 months. We evaluated eventfree survival, defined as the time interval from the date of initial diagnosis to the date of specific change in treatment strategy or recurrence or the last follow-up.

Results: An event (specific change in treatment strategy or recurrence) occurred in 28 patients (28.3\%). No significant difference in event-free survival was found between the first-line observation/medical treatment and local treatment groups $(p=0.509)$. The median Musculoskeletal Tumor Society score of the patients treated with first-line local treatment was 29 (interquartile range [IQR], 23-30), whereas that of the patients managed with first-line observation or medical treatment was 21 (IQR, 19-29.5). First-line observation or medical treatment was more frequently chosen for larger tumors $(p=0.045)$. In the patients treated with local treatment, local recurrence was not related to the surgical margin $(p=0.976)$.
\end{abstract}

Conclusion: Upfront surgery is not advantageous compared to more conservative treatments such as observation or medical treatment for patients with desmoid tumors.

Keywords: Desmoid tumor, Aggressive fibromatosis, Active surveillance, Surgery, MSTS functional score

* Correspondence: shinji104@mail.goo.ne.jp

'Department of Orthopaedic Surgery, Nara Medical University, 840, Shijo-cho, Kashihara-city, Nara 634-8521, Japan

Full list of author information is available at the end of the article

(c) The Author(s). 2021 Open Access This article is licensed under a Creative Commons Attribution 4.0 International License, which permits use, sharing, adaptation, distribution and reproduction in any medium or format, as long as you give appropriate credit to the original author(s) and the source, provide a link to the Creative Commons licence, and indicate if changes were made. The images or other third party material in this article are included in the article's Creative Commons licence, unless indicated otherwise in a credit line to the material. If material is not included in the article's Creative Commons licence and your intended use is not permitted by statutory regulation or exceeds the permitted use, you will need to obtain permission directly from the copyright holder. To view a copy of this licence, visit http://creativecommons.org/licenses/by/4.0/ The Creative Commons Public Domain Dedication waiver (http://creativecommons.org/publicdomain/zero/1.0/) applies to the data made available in this article, unless otherwise stated in a credit line to the data. 


\section{Background}

A desmoid tumor (DT) or aggressive fibromatosis is a "clonal fibroblastic proliferation that arises in the deep soft tissues and is characterized by infiltrative growth and a tendency toward local recurrence but an inability to metastasize even though it may be multifocal in the same limb or body part" [1]. Before the 2000s, surgery with microscopically negative margins was considered the standard of care for patients with DT, which is similar to the treatment approach for soft tissue sarcomas of the extremities owing to the infiltrative growth pattern of DT [2]. However, DT resection often leads to substantial function impairment and cosmetic alterations in patients affected by an otherwise benign disease, without avoiding the high risk of local recurrence despite the wide margins of resection [2]. For this reason, a shift toward more conservative management has been introduced recently [3]. In accordance with this approach, an observation alone strategy has been recommended as the first-line approach in newly diagnosed patients, reserving chemotherapy, a tyrosine kinase inhibitor, radiation, and surgical treatment for cases of disease progression [4]. According to the recent consensus recommendations from the Desmoid Tumor Working Group, management of asymptomatic patients with initial observation, independent of tumor site and size, can be proposed [5]. An earlier decision toward an active treatment is needed for DTs located close to critical structures (e. g., mesenteric or head and neck), and for sites other than the abdominal wall, medical treatment should be considered as the first treatment option in case of progression [5]. In addition, because DT is a benign and symptomatic tumor, studies focusing on patient outcomes in terms of symptoms and function are needed [6].

Our objective was to investigate whether observation or medical treatment is an appropriate first-line management approach for patients with DT. Therefore, we performed a retrospective study to compare the clinical and functional outcomes of initial observation or medical treatment, with initial local treatment (surgery with or without radiotherapy).

\section{Methods}

We retrospectively reviewed the medical files of 253 patients with histologically confirmed DT who were treated at the senior author's institution between 1978 and 2018. As intra-abdominal DT is a completely different disease from extraperitoneal DT with regard to various factors (associated with familial adenomatous polyposis, treatment strategy, and prognosis), patients with intraabdominal DT were excluded from this study [7]. The management of DT has evolved over the decades. Before 2010, we treated DTs with surgery. Recently, we observed patients with newly diagnosed DT following current practice paradigms, that is, observation as the first-line approach. Once patients showed clinical progression or symptoms, we switched to local or medical treatment. We evaluated the patients' characteristics, DT size, treatment approaches, surgical margins, and patient outcomes (Tables 1 and 2). Thirty-seven patients with $<12$ months of follow-up, 113 patients with missing data, and 4 patients referred for tumor recurrence were excluded. The remaining 99 patients were included in this study for further analysis. The characteristics of the included and excluded patients are shown in the Appendix. The median follow-up period was 57 months (interquartile range [IQR], 33-86 months). As first-line management, local treatment was performed in 60 patients (45 patients received surgery alone, and 15 patients received surgery with adjuvant radiotherapy) and observation (16 patients) or medical treatment (16 patients received low-dose chemotherapy, and 7 patients received non-steroidal antiinflammatory drugs [NSAIDs] alone or a combination of NSAIDs and anti-hormonal therapy [tamoxifen]) was chosen for 39 patients. All patient data were retrieved from the patients' medical records. All the patients provided written informed consent for the inclusion of their data in this study. Institutional review board/ethics committee approval was not considered necessary for retrospective studies at the senior author's institution.

We analyzed the prognostic values of age at presentation, sex, DT site and size, previous surgery or trauma in the area of the primary tumor, biopsy technique, initial treatment, year of diagnosis, adjuvant radiotherapy, and surgical margin. We divided the patients into 2 groups according to the tumor site because tumors in the extremities were reported to be associated with a higher local recurrence rate [8].

DT size was defined as the greatest dimension on imaging before any treatment. Low-dose chemotherapy with methotrexate at a dose of $30 \mathrm{mg} / \mathrm{m}^{2}$ plus vinblastine at a dose of $6 \mathrm{mg} / \mathrm{m}^{2}$, as previously reported [9], was administered to 27 patients for a median period of 12 months (IQR, 6-15 months) in the overall therapeutic process. Six (22.2\%) of the patients required repeated low-dose chemotherapy. NSAIDs were administered to 17 patients for a median period of 13 months (IQR, 4.525 months); tyrosine kinase inhibitor, to one patient for 12 months; and a combination of NSAIDs and antihormonal therapy, to 12 patients for a median period of 14 months (IQR, 4.5-22.5 months) in the overall therapeutic process.

Routine clinical and imaging follow-up evaluations were performed at 8 and 12 weeks, and then every 3 months for the first year, followed by every 6 months for the next 4 years and yearly thereafter. Response to medical treatment was assessed on the basis of the DT size 
Table 1 Details of the patients included in this study at baseline

\begin{tabular}{|c|c|c|c|c|}
\hline \multirow[t]{2}{*}{ Variables } & \multirow{2}{*}{$\begin{array}{l}\text { Patients } \\
(n=99 \\
\%)\end{array}$} & \multicolumn{2}{|l|}{ Initial treatment } & \multirow[t]{2}{*}{$P$ value } \\
\hline & & Local treatment $(n=60,60.6 \%)$ & Observation/medical treatment $(n=39,39.4 \%)$ & \\
\hline \multicolumn{5}{|l|}{ Age at diagnosis (years) } \\
\hline Median & 38.2 & 39.4 & 36.1 & \multirow[t]{2}{*}{0.670} \\
\hline IQR & $25.4-47.7$ & $25.5-50.8$ & $23.8-44.3$ & \\
\hline \multicolumn{5}{|l|}{ Sex } \\
\hline Male & $37,37.4 \%$ & $23,38.3 \%$ & $14,35.9 \%$ & \multirow[t]{2}{*}{0.806} \\
\hline Female & $62,62.6 \%$ & $37,61.7 \%$ & $25,64.1 \%$ & \\
\hline \multicolumn{5}{|l|}{ Tumor site } \\
\hline Abdominal wall & $4,4.0 \%$ & $2,3.3 \%$ & $2,5.1 \%$ & \multirow[t]{6}{*}{$0.901^{c}$} \\
\hline Upper extremity & $10,10.1 \%$ & $9,15.0 \%$ & $1,2.6 \%$ & \\
\hline Lower extremity & $39,39.4 \%$ & $21,35.0 \%$ & $18,46.2 \%$ & \\
\hline Girdle & $31,31.3 \%$ & $20,33.3 \%$ & $11,28.2 \%$ & \\
\hline Head and neck & $6,6.1 \%$ & $2,3.3 \%$ & $4,10.3 \%$ & \\
\hline Chest wall & $9,9.1 \%$ & $6,10.0 \%$ & $3,7.7 \%$ & \\
\hline \multicolumn{5}{|l|}{ Tumor size $(\mathrm{cm})$} \\
\hline Median & 8 & 7 & 9 & \multirow[t]{2}{*}{$0.045^{\mathrm{a}}$} \\
\hline IQR & $5-11$ & $5-10$ & $6-13$ & \\
\hline \multicolumn{5}{|l|}{ Clinical presentation } \\
\hline Mass & $42,42.4 \%$ & $23,38.3 \%$ & $19,48.7 \%$ & \multirow[t]{5}{*}{$0.308^{d}$} \\
\hline Pain & $7,7.1 \%$ & $3,5.0 \%$ & $4,10.3 \%$ & \\
\hline Mass + Pain & $46,46.5 \%$ & $33,55.0 \%$ & $13,33.3 \%$ & \\
\hline Functional impairment & $2,2.0 \%$ & 0 & $2,5.1 \%$ & \\
\hline Functional impairment + Pain & $2,2.0 \%$ & $1,1.7 \%$ & $1,2.6 \%$ & \\
\hline \multicolumn{5}{|c|}{ Previous surgery or trauma at the site of the primary tumor } \\
\hline Yes & $14,14.1 \%$ & $9,15.0 \%$ & $5,12.8 \%$ & \multirow[t]{2}{*}{$0.721^{b}$} \\
\hline No & $85,85.9 \%$ & $51,85.0 \%$ & $34,87.2 \%$ & \\
\hline \multicolumn{5}{|l|}{ Year of diagnosis } \\
\hline 1999-2009 & $61,61.6 \%$ & $48,80.0 \%$ & $13,33.3 \%$ & \multirow[t]{2}{*}{$<0.001^{\mathrm{a}}$} \\
\hline 2010-2018 & $38,38.4 \%$ & $12,20.0 \%$ & $26,66.7 \%$ & \\
\hline
\end{tabular}

IQR interquartile range. ${ }^{\text {T}}$ The difference was significant. ${ }^{\mathrm{b}}$ The Fisher exact test was used. ${ }^{\mathrm{c}}$ Comparison of extremity and non-extremity. ${ }^{\mathrm{d}}$ Comparison of mass alone and the others

reduction, along with computed tomography (CT) or magnetic resonance imaging (MRI) for the best response, and was rated as "complete response," "partial response," "stable disease," or "progressive disease" according to the modified Response Evaluation Criteria in Solid Tumors (version 1.1), which assesses the tumor extent on the basis of the sum of the longest diameter of all target lesions [10]. Functional scores according to the Musculoskeletal Tumor Society (MSTS) scoring system were collected for patients with extremity DTs when possible [11]. The MSTS score was based on 3 general factors (pain, function, and emotional acceptance) and 3 lower limb factors (use of supports, ability to walk, and gait) [11].
The chi-square or Fisher exact test was used to evaluate the association between categorical variables, as appropriate. The differences between the independent continuous variables were statistically analyzed using the Mann-Whitney $U$ test for nonparametric analyses. Event-free survival was defined as the time interval from the date of initial diagnosis to the date of specific change in treatment strategy or recurrence or the last follow-up. The specific change in treatment strategy was defined as the change from observation or NSAIDs/anti-hormonal therapy to low-dose chemotherapy or surgery, or the change from low-dose chemotherapy to surgery. Recurrence-free survival was defined as the time interval from the date of initial diagnosis to the date of 
Table 2 Treatment characteristics and outcome of the patients included in this series

\begin{tabular}{|c|c|c|c|}
\hline \multirow[t]{2}{*}{ Variable } & \multirow{2}{*}{$\begin{array}{l}\text { Patients } \\
(n=99 \\
\%)\end{array}$} & \multicolumn{2}{|l|}{ Initial treatment } \\
\hline & & Local treatment $(n=60,60.6 \%)$ & Observation/medical treatment $(n=39,39.4 \%)$ \\
\hline \multicolumn{4}{|l|}{ Biopsy } \\
\hline Core needle biopsy & $70,70.7 \%$ & $38,63.3 \%$ & $32,82.1 \%$ \\
\hline Open biopsy & $29,29.3 \%$ & $22,36.7 \%$ & $7,17.9 \%$ \\
\hline \multicolumn{4}{|c|}{ Total number of surgeries } \\
\hline Median & 1 & 1 & 0 \\
\hline IQR & $0-1$ & $1-2$ & $0-0$ \\
\hline \multicolumn{4}{|l|}{ NSAIDs } \\
\hline No & $82,82.8 \%$ & $60,100.0 \%$ & $22,56.4 \%$ \\
\hline Yes & $17,17.2 \%$ & 0 & $17,43.6 \%$ \\
\hline \multicolumn{4}{|c|}{ Tyrosine kinase inhibitor } \\
\hline No & $98,99.0 \%$ & $60,100.0 \%$ & $38,97.4 \%$ \\
\hline Yes & $1,1.0 \%$ & 0 & $1,2.6 \%$ \\
\hline \multicolumn{4}{|c|}{ Anti-hormonal therapy + NSAIDs } \\
\hline No & $87,87.9 \%$ & $59,98.3 \%$ & $28,71.8 \%$ \\
\hline Yes & $12,12.1 \%$ & $1,1.7 \%$ & $11,28.2 \%$ \\
\hline \multicolumn{4}{|c|}{ Low-dose chemotherapy } \\
\hline No & $72,72.7 \%$ & $56,93.3 \%$ & $16,41.0 \%$ \\
\hline Yes & $27,27.3 \%$ & $4,6.7 \%$ & $23,59.0 \%$ \\
\hline \multicolumn{4}{|c|}{ Follow up period (months) } \\
\hline Median & 57 & 58.5 & 55 \\
\hline IQR & $33-86$ & $35-96$ & $27-85$ \\
\hline \multicolumn{4}{|l|}{ Event } \\
\hline No & $71,71.7 \%$ & $41,68.3 \%$ & $30,76.9 \%$ \\
\hline Yes & $28,28.3 \%$ & $19,31.7 \%$ & $9,23.1 \%$ \\
\hline \multicolumn{4}{|c|}{ Interval between the diagnosis and event } \\
\hline Median & 18 & 19 & 13 \\
\hline IQR & $9-32$ & $9-36$ & $9-24$ \\
\hline \multicolumn{4}{|l|}{ MSTS score } \\
\hline Median & 26 & 29 & 21 \\
\hline IQR & $21-30$ & $23-30$ & $19-29.5$ \\
\hline
\end{tabular}

IQR interquartile range, NSAIDs non-steroidal anti-inflammatory drugs, MSTS Musculoskeletal Tumor Society

recurrence or the last follow-up. Event- and recurrencefree survival were evaluated with the Kaplan-Meier survival analysis, and survival curves were compared using a log-rank test. A $p$ value $<0.05$ was considered statistically significant. Analyses were performed using IBM SPSS version 25.0 (IBM Co., Armonk, NY, USA) and JMP 14 (SAS Institute Inc., Cary, NC, USA).

\section{Results}

Overall, events (specific change in treatment strategy or recurrence) occurred in 28 patients (28.3\%), and none of the patients died of disease. The univariate analysis revealed that male sex had a significant association with unfavorable event-free survival $(p=0.024$; Table 3$)$. No significant difference in event-free survival was observed between the first-line observation/medical treatment and local treatment groups ( $p=0.509$; Table 3, Fig. 1 ).

First-line observation or medical treatment was more frequently chosen for larger tumors $(p=0.045)$ and between 2010 and 2018 ( $p<0.001$; Table 1). The number of surgical operations in the overall therapeutic process was higher in the first-line local treatment group than in the first-line observation or medical treatment group $(p<0.001$; Table 2). The number of patients who received low-dose chemotherapy in the overall therapeutic process was significantly higher in the first-line 
Table 3 Univariate predictors of event-free survival

\begin{tabular}{|c|c|c|c|}
\hline Variable & Patients (n) & 5-year event-free survival $(95 \% \mathrm{Cl}, \%)$ & $P$ value \\
\hline \multicolumn{4}{|l|}{ Age at diagnosis (years) } \\
\hline$\leq 30$ & 35 & $70.2(52.8-83.3)$ & \multirow[t]{2}{*}{0.764} \\
\hline$>30$ & 64 & $69.8(56.3-80.6)$ & \\
\hline \multicolumn{4}{|l|}{ Sex } \\
\hline Male & 37 & $56.3(39.3-71.9)$ & \multirow[t]{2}{*}{$0.024^{a}$} \\
\hline Female & 62 & $77.8(64.4-87.1)$ & \\
\hline \multicolumn{4}{|l|}{ Tumor site } \\
\hline Extremities & 49 & $66.9(51.8-79.1)$ & \multirow[t]{2}{*}{0.522} \\
\hline Non-extremities & 50 & $73.1(58.0-84.3)$ & \\
\hline \multicolumn{4}{|l|}{ Tumor size $(\mathrm{cm})$} \\
\hline$\leq 5$ & 25 & $82.8(61.8-93.5)$ & \multirow[t]{3}{*}{0.345} \\
\hline $5<,<10$ & 37 & $71.3(54.2-83.9)$ & \\
\hline$\geq 10$ & 37 & $60.1(41.9-75.9)$ & \\
\hline \multicolumn{4}{|c|}{ Previous surgery or trauma at the site of the primary tumor } \\
\hline Yes & 14 & $77.1(47.9-92.5)$ & \multirow[t]{2}{*}{0.998} \\
\hline No & 85 & $68.8(57.4-78.3)$ & \\
\hline \multicolumn{4}{|l|}{ Year of diagnosis } \\
\hline 1999-2009 & 61 & $64.9(51.1-76.6)$ & \multirow[t]{2}{*}{0.372} \\
\hline $2010-2018$ & 38 & $78.8(63.0-89.0)$ & \\
\hline \multicolumn{4}{|l|}{ Biopsy } \\
\hline Core needle biopsy & 70 & $72.9(60.4-82.6)$ & \multirow[t]{2}{*}{0.190} \\
\hline Open biopsy & 29 & $63.2(43.7-79.2)$ & \\
\hline \multicolumn{4}{|l|}{ Initial treatment } \\
\hline Local treatment & 60 & $66.8(53.0-78.2)$ & \multirow[t]{2}{*}{0.509} \\
\hline Observation/medical treatment & 39 & $75.2(58.6-86.7)$ & \\
\hline
\end{tabular}

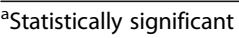

observation or medical treatment group than in the first-line local treatment group $(p<0.001$; Table 2$)$. The median MSTS score of the 39 patients was 26 (IQR, 21$30)$. The median MSTS score of the 23 patients treated with first-line local treatment was 29 (IQR, 23-30), whereas that of the 16 patients managed with first-line observation or medical treatment was 21 (IQR, 19-29.5).

The univariate analysis for the patients initially treated with local treatment revealed that male sex was significantly associated with unfavorable recurrence-free survival $(p=0.021$; Table 4$)$. The surgical margins of the initial surgery in the surgery alone group were R0 (microscopic complete resection) in 23 patients, R1 (microscopic incomplete resection) in 16 patients, and R2 (macroscopic incomplete resection) in 6 patients. The surgical margins in the initial surgery in the "surgery with adjuvant radiotherapy" group were R0 in 6 patients, R1 in 8 patients, and R2 in 1 patient. The recurrence-free survival rates were not significantly different according to the surgical margin of the initial surgery and the presence of adjuvant radiotherapy in the univariate analysis (Table 4). The univariate analysis for the patients initially managed with observation or medical treatment revealed that none of the 8 variables (age, sex, tumor site, tumor size, previous surgery or trauma at the site of the primary tumor, year of diagnosis, biopsy, and initial treatment [observation $+/$-tamoxifen or NSAIDs vs. low-dose chemotherapy]) were significantly associated with event-free survival.

Among the patients who received low-dose chemotherapy in the overall therapeutic process, 3 (11.1\%) experienced a partial response; 23 (85.1\%), stable disease; and 1 (3.7\%), disease progression. Among the patients treated with NSAIDs in the overall therapeutic process, 11 (64.7\%) experienced stable disease and 6 (35.3\%) experienced disease progression. The patient treated with a tyrosine kinase inhibitor exhibited a stable disease. Among the patients treated with combined NSAIDs and anti-hormonal therapy in the overall therapeutic process, 9 (75.0\%) experienced stable disease and $3(25.0 \%)$ displayed disease progression. Among the 16 patients who were managed with first-line observation, 7 (43.8\%) 


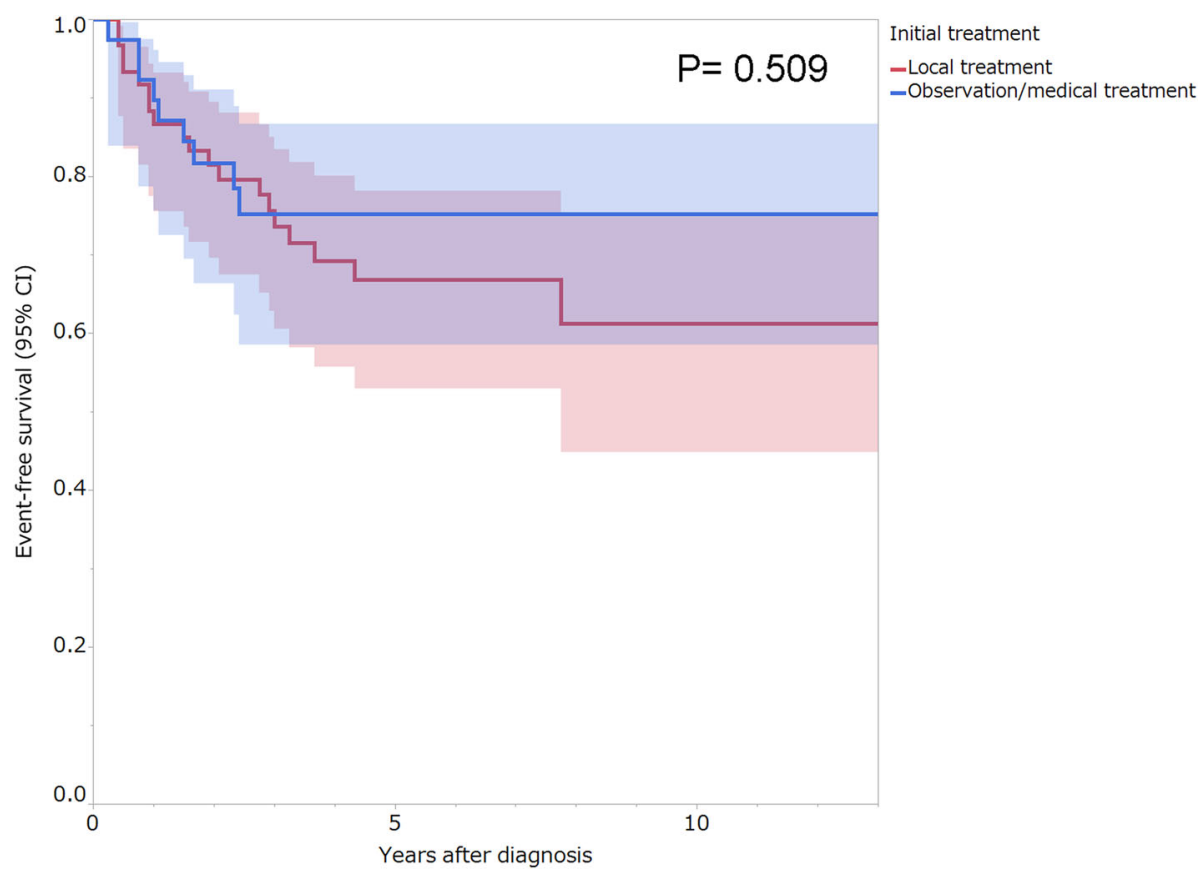

Fig. 1 Kaplan-Meier analysis of event-free survival according to initial treatment. The shading surrounding the curves represents the 95\% confidence interval

experienced a disease progression; 2 (12.5\%), stable disease; and 7 (43.8\%), spontaneous regression.

\section{Discussion}

Our results showed similar event-free survival between observation or medical treatment and local treatment as the first-line approach. The published studies regarding active surveillance for DT are summarized in Table 5 [3, 12-25]. Of patients under active surveillance, 4-37\% spontaneously regressed, $17-92 \%$ had stable disease, and $4-59 \%$ had tumor progression [3, 12-25]. Kito et al. [26] performed a systematic review comparing surgery and active surveillance. They reported that the exacerbation rate (exacerbation; recurrence after surgery or progressive disease after active surveillance) was significantly higher in the surgery group (odds ratio, 1.32; 95\% confidence interval $[\mathrm{CI}], 1.01-1.73 ; p=0.05$ ). Thus, our results confirmed that the use of first-line observation or medical treatment is appropriate for DT. A recent joint global consensus-based guideline from the Desmoid Tumor Working Group recommended that first-line treatment should start with a plan for active surveillance [5]. Indications for active treatment include pain, with or without radiological evidence of progression, functional symptoms, or patient request [27]. According to a recent systematic literature review of active surveillance for patients with DTs, the median follow-up time of the patients was reported in 12 studies and ranged from 8 to 73 months [28]. In the case of subsequent progression or a significant increase in symptom burden, a decision toward treatment may be considered and assessed with at least 3 further assessments and possibly not before 1 year after the initial diagnosis [29].

This study showed poor extremity functional outcomes in the first-line observation/medical treatment group. However, larger tumors were more frequently managed with first-line observation or medical treatment, which may explain the reason for the poor extremity functional outcome in the first-line observation/ medical treatment group. Newman et al. [6] reported that the Patient-reported Outcomes Measurement Information System function scores were lowest among patients who underwent $\geq 2$ surgical interventions and among those treated with surgery and radiation at any time. Duhil de Benaze et al. [30] analyzed the long-term quality of life of pediatric patients with DT by using the Child Health Questionnaire. They did not find any difference in the quality-of-life scores between patients who underwent first-line observation and those who received more aggressive therapies (surgery or chemotherapy). Pain is not strictly correlated with DT progression; some stable DT may be painful, while some progressive DT may not be painful; sometimes, pain can be the consequence of previous locoregional treatments rather than the disease [31]. Therefore, unless the tumors are located in sites at risk of potentially life-threatening conditions, the most meaningful end point for evaluating the effectiveness of treatment strategies for DTs may be the impact on patient symptoms and function, rather than the traditional oncologic metrics such as local 
Table 4 Univariate predictors of recurrence-free survival in patients initially treated with local treatment

\begin{tabular}{|c|c|c|c|}
\hline Variable & Patients (n) & 5-year recurrence-free survival $(95 \% \mathrm{Cl}, \%)$ & $P$ value \\
\hline \multicolumn{4}{|c|}{ Age at diagnosis (years) } \\
\hline$\leq 30$ & 22 & $72.4(50.6-87.1)$ & \multirow[t]{2}{*}{0.711} \\
\hline$>30$ & 38 & $62.8(44.6-78.0)$ & \\
\hline \multicolumn{4}{|l|}{ Sex } \\
\hline Male & 23 & $50.2(30.1-70.2)$ & \multirow[t]{2}{*}{$0.021^{\mathrm{a}}$} \\
\hline Female & 37 & $76.9(58.4-88.8)$ & \\
\hline \multicolumn{4}{|l|}{ Tumor site } \\
\hline Extremities & 30 & $70.2(50.4-84.6)$ & \multirow[t]{2}{*}{0.571} \\
\hline Non-extremities & 30 & $63.0(43.3-79.2)$ & \\
\hline \multicolumn{4}{|l|}{ Tumor size $(\mathrm{cm})$} \\
\hline$\leq 5$ & 17 & $86.9(59.6-96.7)$ & \multirow[t]{3}{*}{0.295} \\
\hline $5<,<10$ & 25 & $62.1(41.5-79.1)$ & \\
\hline$\geq 10$ & 18 & $55.2(29.2-78.6)$ & \\
\hline \multicolumn{4}{|c|}{ Previous surgery or trauma at the site of the primary tumor } \\
\hline Yes & 9 & $77.8(42.1-94.4)$ & \multirow[t]{2}{*}{0.936} \\
\hline No & 51 & $65.0(49.9-91.7)$ & \\
\hline \multicolumn{4}{|l|}{ Year of diagnosis } \\
\hline 1999-2009 & 48 & $65.1(49.5-78.0)$ & \multirow[t]{2}{*}{0.750} \\
\hline $2010-2018$ & 12 & $75.0(44.8-91.7)$ & \\
\hline \multicolumn{4}{|l|}{ Biopsy } \\
\hline Core needle biopsy & 38 & $70.4(52.8-83.5)$ & \multirow[t]{2}{*}{0.251} \\
\hline Open biopsy & 22 & $60.6(38.2-79.2)$ & \\
\hline \multicolumn{4}{|l|}{ Adjuvant radiotherapy } \\
\hline No & 45 & $73.0(57.2-84.5)$ & \multirow[t]{2}{*}{0.110} \\
\hline Yes & 15 & $48.6(23.8-74.1)$ & \\
\hline \multicolumn{4}{|l|}{ Surgical margin } \\
\hline Ro & 29 & $67.7(48.4-82.4)$ & \multirow[t]{2}{*}{0.976} \\
\hline $\mathrm{R} 1 / 2$ & 31 & $66.4(46.5-81.8)$ & \\
\hline
\end{tabular}

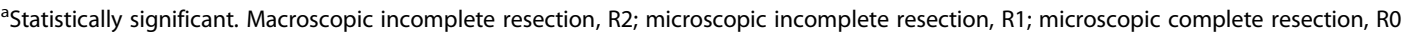

recurrence and disease progression on imaging $[6,23]$. Thus, in the future, prospective data on function and quality of life must be collected from a larger cohort of patients with DTs.

In this study, observation or medical treatment was more frequently selected for larger tumors. Primary resection should be considered for small tumors, and medical therapy should be considered for large tumors [30]. Moreover, in this study, the patients treated with firstline local treatment needed less low-dose chemotherapy in their overall treatment than those managed with firstline observation or medical treatment. Duhil de Benaze et al. [30] and Sparber-Sauer et al. [32] reported the same results as ours. As first-line local treatments were more frequently selected for smaller tumors, low-dose chemotherapy might be less frequently indicated.
Our study shows that male sex had a significant association with unfavorable event- and recurrence-free survival. Most previous studies reported no association between sex and outcome [14, 16, 19, 21, 23, 33-35], while Huang et al. [36] reported that male sex was a predictor of local recurrence in the univariate analysis. Hong et al. [37] reported that testosterone regulates $\beta$ catenin protein levels and proliferation rates in DT. They found the possibility of therapeutic use of testosterone blockade in DT.

Our results showed that neither surgical margin nor adjuvant radiotherapy affected local recurrence. In 2017, Janssen et al. [38] performed a meta-analysis of the influence of surgical margins and adjuvant radiotherapy on local recurrence after resection of sporadic DT. In patients treated with surgical resection alone, the risk of local 


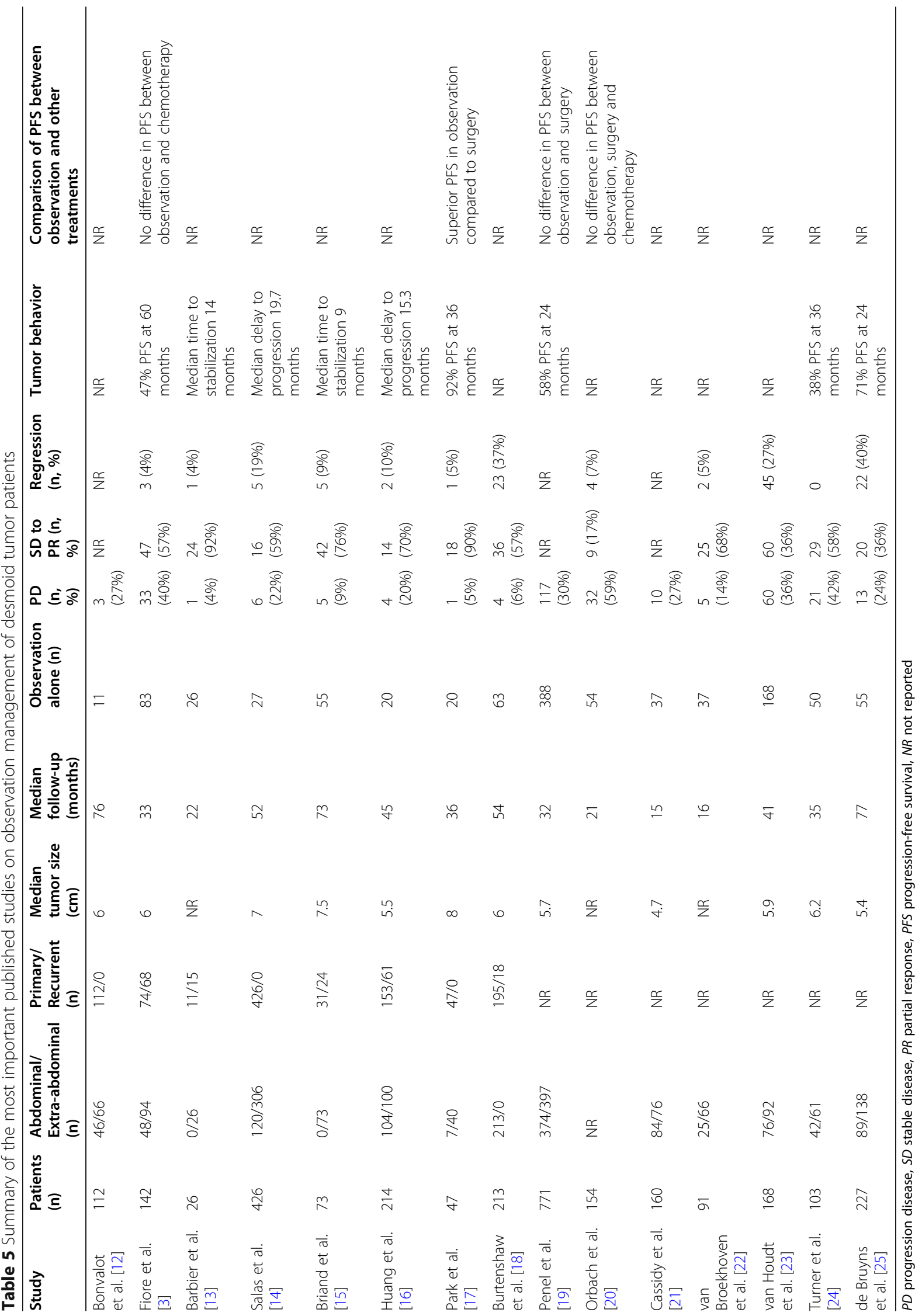


recurrence was almost twofold higher than that in patients with microscopically positive resection margins (risk ratio [RR], 1.78; 95\% CI, 1.40-2.26) [38]. Adjuvant radiotherapy after surgery with negative margins had no detectable benefit on recurrence [38]. By contrast, after incomplete surgical resection, adjuvant radiotherapy improved the recurrence rates both in the patients with primary tumors (RR, 1.54; 95\% CI, 1.05-2.27) and in those with recurrent DF (RR, 1.60; 95\% CI, 1.12-2.28) [38]. Contrary to our results, evidence supports the effect of negative margins and adjuvant radiotherapy on local recurrence [38]. Turner et al. [24] suggested that negative margins should be the goal, but should not be pursued at the expense of significant functional loss. They suggested one additional consideration, namely tumor behavior [24]. Any residual from an aggressive tumor should be presumed to be at high risk of regrowth and that negative margins are therefore more important in this group [24]. On the other hand, more indolent disease may shift the balance in favor of minimizing surgical morbidity in cases that still require surgery [24].

Our study has several limitations. First, it was a retrospective study with inherent limitations and risk of selection bias. Smaller tumors were excluded from this study (Appendix). Second, the tumor size was not uniform among the first-line treatment groups. This may have affected the event-free survival or functional outcome. Third, a power analysis was not performed, and a risk of type II error due to the small sample size was present. If an adequate number of patients is gathered in the future, significant differences may appear regarding the other variables in this study. Forth, we were not able to compare the event-free survival between first-line observation and medical treatment groups due to the small sample size. Kasper et al. stated that a stepwise therapy escalation from an initial, less toxic treatment including observation to more toxic agents seems reasonable for progressive DTs [29]. These limitations should be considered in the analysis of our study results.

\section{Conclusions}

Upfront surgery is not advantageous compared to more conservative treatments such as observation or medical treatment for patients with desmoid tumors.

\section{Supplementary Information}

The online version contains supplementary material available at https://doi. org/10.1186/s12891-020-03897-9.

Additional file 1: Appendix. Patients characteristics of included or

excluded patients in this study.

\section{Abbreviations}

DT: Desmoid tumor; NSAID: Non-steroidal anti-inflammatory drug; IQR: Interquartile range; CT: Computed tomography; MRI: Magnetic resonance imaging; MSTS: Musculoskeletal Tumor Society

\section{Acknowledgments}

The authors thank all the patients and their families.

\section{Authors' contributions}

ST designed the study, analyzed the data, and wrote the manuscript. PT designed the study and gathered the data. MA designed the study, performed the statistical analyses, and wrote a part of the manuscript. AK and YT integrated the study. MC, DMD, and AL were involved in the care of the patients included in this study and integrated the study. AFM designed the study and revised the manuscript. CE was involved in the care of the patients included in this study, designed the study, gathered the data, and revised the manuscript. All authors have read and approved the final manuscript.

\section{Funding}

None.

\section{Availability of data and materials}

The datasets generated, analyzed, or both during the present study are not publicly available because of privacy problems but are available from the corresponding author on reasonable request.

Ethics approval and consent to participate

All patients provided written informed consent for their data to be included in any possible future scientific study. Institutional review board/ethics committee approval is not considered necessary for retrospective studies at the senior author's institution.

\section{Consent for publication}

All the patients provided written informed consent for their data to be included in any possible future scientific study.

\section{Competing interests}

The authors declare that they have no competing interests.

\section{Author details}

'Department of Orthopaedic Surgery, Nara Medical University, 840, Shijo-cho, Kashihara-city, Nara 634-8521, Japan. ${ }^{2}$ Department of Orthopaedic Oncology, IRCCS Istituto Ortopedico Rizzoli, Via Pupilli 1, 40136 Bologna, Italy. ${ }^{3}$ First Department of Orthopaedics, National and Kapodistrian University of Athens, School of Medicine, 41 Ventouri Street, Holargos, 15562 Athens, Greece. ${ }^{4}$ Department of Health and Welfare Services, National Institute of Public Health, 2-3-6 Minami, Wako-shi, Saitama 351-0197, Japan. ${ }^{5}$ Department of Rehabilitation Medicine, Nara Medical University, 840 Shijo-cho,

Kashihara-city, Nara 634-8521, Japan. ${ }^{6}$ Department of Medical Oncology, IRCC S Istituto Ortopedico Rizzoli, Via Pupilli 1, 40136 Bologna, Italy.

Received: 21 June 2020 Accepted: 21 December 2020

Published online: 05 January 2021

\section{References}

1. Goldblum JR, Fletcher JA. Desmoid-type fibromatosis. In: Fletcher CDM, Bridge JA, Hogendoorn P, Mertens F, editors. WHO classification of tumours of soft tissue and bone. Lyon: IARC; 2013. p. 72-3.

2. Kasper B, Baumgarten C, Bonvalot $S$, Haas R, Haller F, Hohenberger $P$, et al. Management of sporadic desmoid-type fibromatosis: a European consensus approach based on patients' and professionals' expertise-a sarcoma patients EuroNet and European Organisation for Research and Treatment of Cancer/soft tissue and bone sarcoma group initiative. Eur J Cancer. 2015;51: 127-36

3. Fiore M, Rimareix F, Mariani L, Domont J, Collini P, Le Péchoux C, et al. Desmoid-type fibromatosis: a front-line conservative approach to select patients for surgical treatment. Ann Surg Oncol. 2009;16:2587-93.

4. Kasper B, Baumgarten C, Garcia J, Bonvalot S, Haas R, Haller F, et al. An update on the management of sporadic desmoid-type fibromatosis: a European consensus initiative between sarcoma PAtients EuroNet (SPAEN) 
and European Organization for Research and Treatment of Cancer (EORTC)/ soft tissue and bone sarcoma group (STBSG). Ann Oncol. 2017;28:2399-408.

5. Desmoid Tumor Working Group. The management of desmoid tumours: a joint global consensus-based guideline approach for adult and paediatric patients. Eur J Cancer. 2020;127:96-107.

6. Newman ET, Lans J, Kim J, Ferrone M, Ready J, Schwab J, et al. PROMIS function scores are lower in patients who underwent more aggressive local treatment for desmoid tumors. Clin Orthop Relat Res. 2020;478:563-77.

7. Slowik V, Attard T, Dai H, Shah R, Septer S. Desmoid tumors complicating familial adenomatous polyposis: a meta-analysis mutation spectrum of affected individuals. BMC Gastroenterol. 2015;15:84.

8. Bishop AJ, Landry JP, Roland CL, Ratan R, Feig BW, Moon BS, et al. Certain risk factors for patients with desmoid tumors warrant reconsideration of local therapy strategies. Cancer. 2020;126:3265-73.

9. Azzarelli A, Gronchi A, Bertulli R, Tesoro JD, Baratti D, Pennacchioli E, et al. Low-dose chemotherapy with methotrexate and vinblastine for patients with advanced aggressive fibromatosis. Cancer. 2001;92:1259-64.

10. Eisenhauer EA, Therasse P, Bogaerts J, Schwartz LH, Sargent D, Ford R, et al. New response evaluation criteria in solid tumours: revised RECIST guideline (version 1.1). Eur J Cancer. 2009;45:228-47.

11. Enneking WF, Dunham W, Gebhardt MC, Malawar M, Pritchard DJ. A system for the functional evaluation of reconstructive procedures after surgical treatment of tumors of the musculoskeletal system. Clin Orthop Relat Res. 1993;286:241-6

12. Bonvalot S, Eldweny H, Haddad V, Rimareix F, Missenard G, Oberlin O, et al. Extra-abdominal primary fibromatosis: aggressive management could be avoided in a subgroup of patients. Eur J Surg Oncol. 2008;34:462-8.

13. Barbier $O$, Anract P, Pluot E, Larouserie F, Sailhan F, Babinet A, et al. Primary or recurring extra-abdominal desmoid fibromatosis: assessment of treatment by observation only. Orthop Traumatol Surg Res. 2010;96:884-9.

14. Salas S, Dufresne A, Bui B, Blay J-Y, Terrier P, Ranchere-Vince D, et al. Prognostic factors influencing progression-free survival determined from a series of sporadic desmoid tumors: a wait-and-see policy according to tumor presentation. J Clin Oncol. 2011;29:3553-8.

15. Briand S, Barbier O, Biau D, Bertrand-Vasseur A, Larousserie F, Anract $P$, et al. Wait-and-see policy as a first-line management for extra-abdominal desmoid tumors. J Bone Joint Surg Am. 2014;96:631-8.

16. Huang K, Wang CM, Chen JG, Du CY, Zhou Y, Shi YQ, et al. Prognostic factors influencing event-free survival and treatments in desmoid-type fibromatosis: analysis from a large institution. Am J Surg. 2014:207:847-54.

17. Park JS, Nakache Y-P, Katz J, Boutin RD, Steffner RJ, Monjazeb AM, et al. Conservative management of desmoid tumors is safe and effective. J Surg Res. 2016;205:115-20.

18. Burtenshaw SM, Cannell AJ, McAlister ED, Siddique S, Kandel R, Blackstein $M E$, et al. Toward observation as first-line management in abdominal desmoid tumors. Ann Surg Oncol. 2016;23:2212-9.

19. Penel N, Le Cesne A, Bonvalot S, Giraud A, Bompas E, Rios M, et al. Surgical versus non-surgical approach in primary desmoid-type fibromatosis patients: a nationwide prospective cohort from the French sarcoma group. Eur J Cancer. 2017;83:125-31.

20. Orbach D, Brennan B, Bisogno G, Van Noesel M, Minard-Colin V, Daragjati J, et al. The EpSSG NRSTS 2005 treatment protocol for desmoid-type fibromatosis in children: an international prospective case series. Lancet Child Adolesc Health. 2017;1:284-92.

21. Cassidy MR, Lefkowitz RA, Long N, Qin L-X, Kirane A, Sbaity E, et al. Association of MRI T2 signal intensity with desmoid tumor progression during active observation: a retrospective cohort study. Ann Surg. 2020;271: 748-55.

22. van Broekhoven DLM, Verschoor AJ, van Dalen T, Grünhagen DJ, den Bakker MA, Gelderblom H, et al. Outcome of nonsurgical management of extraabdominal, trunk, and abdominal wall desmoid-type fibromatosis: a population-based study in the Netherlands. Sarcoma. 2018;2018:5982575.

23. van Houdt WJ, Husson O, Patel A, Jones RL, Smith MJF, Miah AB, et al. Outcome of primary desmoid tumors at all anatomic locations initially managed with active surveillance. Ann Surg Oncol. 2019;26:4699-706.

24. Turner B, Alghamdi M, Henning J-W, Kurien E, Morris D, Bouchard-Fortier A, et al. Surgical excision versus observation as initial management of desmoid tumors: a population-based study. Eur J Surg Oncol. 2019:45:699-703.

25. de Bruyns A, Li H, MacNeil A, Simmons C, Clarkson P, Goddard K, et al. Evolving practice patterns over two decades (1993-2013) in the management of desmoid-type fibromatosis in British Columbia. Clin Oncol (R Coll Radiol). 2020;32:e102-10.

26. Kito M, Ogose A, Yoshida M, Nishida Y. Usefulness of surgical treatment for asymptomatic patients with extra-peritoneal desmoid-type fibromatosis: a systematic review and meta-analysis. Jpn J Clin Oncol. 2020;50:574-80.

27. Bonvalot $\mathrm{S}$, Ternès $\mathrm{N}$, Fiore $\mathrm{M}$, Bitsakou $\mathrm{G}$, Colombo $\mathrm{C}$, Honoré $\mathrm{C}$, et al. Spontaneous regression of primary abdominal wall desmoid tumors: more common than previously thought. Ann Surg Oncol. 2013;20:4096-102.

28. Timbergen MJM, Schut A-RW, Grünhagen DJ, Sleijfer S, Verhoef C. Active surveillance in desmoid-type fibromatosis: a systematic literature review. Eur J Cancer. 2020;137:18-29.

29. Kasper B, Raut CP, Gronchi A. Desmoid tumors: to treat or not to treat, that is the question. Cancer. 2020. https://doi.org/10.1002/cncr.33233.

30. Duhil de Bénazé G, Vigan M, Corradini N, Minard-Colin V, Marie-Cardine A, Verite $C$, et al. Functional analysis of young patients with desmoid-type fibromatosis: Initial surveillance does not jeopardize long term quality of life. Eur J Surg Oncol. 2020:46:1294-300.

31. Gronchi A, Colombo C, Le Péchoux C, Dei Tos AP, Le Cesne A, Marrari A, et al. Sporadic desmoid-type fibromatosis: a stepwise approach to a nonmetastasising neoplasm - a position paper from the Italian and the French sarcoma group. Ann Oncol. 2014;25:578-83.

32. Sparber-Sauer M, Seitz G, von Kalle T, Vokuhl C, Leuschner I, Scheer M, et al. Systemic therapy of aggressive fibromatosis in children and adolescents: report of the cooperative Weichteilsarkom Studiengruppe (CWS). Pediatr Blood Cancer. 2018;65:e26943.

33. He XD, Zhang YB, Wang L, Tian ML, Liu W, Qu Q, et al. Prognostic factors for the recurrence of sporadic desmoid-type fibromatosis after macroscopically complete resection: analysis of 114 patients at a single institution. Eur J Surg Oncol. 2015;41:1013-9.

34. Colombo C, Miceli R, Le Péchoux C, Palassini E, Honoré C, Stacchiotti S, et al. Sporadic extra abdominal wall desmoid-type fibromatosis: surgical resection can be safely limited to a minority of patients. Eur J Cancer. 2015; 51:186-92.

35. Crago AM, Denton B, Salas S, Dufresne A, Mezhir JJ, Hameed M, et al. A prognostic nomogram for prediction of recurrence in desmoid fibromatosis. Ann Surg. 2013;258:347-53.

36. Huang K, Fu H, Shi Y-Q, Zhou Y, Du C-Y. Prognostic factors for extraabdominal and abdominal wall desmoids: a 20-year experience at a single institution. J Surg Oncol. 2009;100:563-9.

37. Hong H, Nadesan P, Poon R, Alman BA. Testosterone regulates cell proliferation in aggressive fibromatosis (desmoid tumour). Br J Cancer. 2011; 104:1452-8.

38. Janssen ML, van Broekhoven DLM, Cates JMM, Bramer WM, Nuyttens JJ, Gronchi A, et al. Meta-analysis of the influence of surgical margin and adjuvant radiotherapy on local recurrence after resection of sporadic desmoid-type fibromatosis. Br J Surg. 2017:104:347-57.

\section{Publisher's Note}

Springer Nature remains neutral with regard to jurisdictional claims in published maps and institutional affiliations.

Ready to submit your research? Choose BMC and benefit from:

- fast, convenient online submission

- thorough peer review by experienced researchers in your field

- rapid publication on acceptance

- support for research data, including large and complex data types

- gold Open Access which fosters wider collaboration and increased citations

- maximum visibility for your research: over $100 \mathrm{M}$ website views per year

At $\mathrm{BMC}$, research is always in progress.

Learn more biomedcentral.com/submissions 